\title{
LA MUJER, LA CREATIVIDAD \\ Y EL ETERNO PRESENTE
}

\author{
POR \\ ZULMA NELLY MARTINEZ \\ McGill University
}

Este trabajo se elabora a partir de la premisa de que el movimiento de liberación de la mujer es parte intrínseca de un proceso general de liberación en el mundo de Occidente. Para mejor comprender este proceso es esencial, por un lado, relacionar la cuestión feminista con la práctica desconstructivista francesa (en particular la elaborada por Jacques Derrida); es imprescindible, por el otro, vincularla a las sorprendentes revelaciones de la física contemporánea y teorías cuánticas. Para esto último nos hemos apoyado en la propuesta del físico contemporáneo David Bohm sobre el orden implícito y/o no manifiesto, el cual se opone al orden de «todos los días»: el explícito o manifiesto.

En efecto, así como el logocentrismo tradicional (que el desconstructivismo impugna) se apoya en la visión del universo newtoniano, el desconstructivismo se hace eco de la experiencia de la nueva física. Así como el logocentrismo y la física tradicional (en su afán de orden de verdad y de razón) se descubren como esencialmente masculinos, el desconstructivismo y la física actual (en tanto desafían el orden establecido, la conciencia razonante y las verdades consagradas) se anuncian como reivindicadores de lo femenino.

(E1 paralelismo que establecemos no es arbitrario, ya que tradicionalmente el hombre ha tratado a la naturaleza, así como a la mujer, como objetos de conocimiento y de consecuente posesión. La conocida referencia de Francis Bacon al «imperio del hombre sobre el mundo» debe complementarse con la idea del imperio del hombre sobre la mujer.)

No es accidente, por tanto, que a la par de los textos feministas y desconstructivistas, actualmente proliferen un gran número de trabajos que intentan poner al alcance de los no iniciados las revelaciones de la nueva física. El actual momento histórico pareciera querer decirnos que no sólo la mujer, sino también el lenguaje y el universo material y últimamente 
el hombre mismo (el varón de la especie), ávidamente reclaman una liberación. Esta liberación debe entenderse como la toma de conciencia de las vastas regiones de la experiencia que la tradición ha reprimido al exiliarlas a las profundidades de la realidad. Lo que últimamente se ha reprimido, por tanto, y lo que debe liberarse, es la energía creadora que desde los abismos de la realidad (los abismos de la mente, el lenguaje y la materia) perennemente busca transformar el mundo. O, en palabras de Derri$\mathrm{da}$, perennemente persigue desconstruirlo y reconstruirlo.

En tanto consideramos que a nivel social la represión de la mujer conforma la represión «arquetípica» (a partir de la cual se han «modelado», por así decirlo, las innúmeras represiones que articulan nuestra realidad), creemos que la liberación de la mujer (y, por extensión, de lo femenino) es esencial para la realización de las demás, cualquiera sea la naturaleza de las mismas.

Es de notar que existe una marcada correlación entre la sujeción del mundo físico y/o de la mujer y la sujeción de los pueblos que representan lo femenino: lo irracional, la «no verdad». Pueblos que en opinión de los creadores de la cultura y detentadores del poder tampoco poseen la facultad de elaborar un destino propio. De ahí que sea esencial subyugarlos (como se subyuga a la mujer) al imperio del logos, a la autoridad de la razón.

Apoyándose en el logos (simultáneamente razón y verbo), la cultura de Occidente se ha empeñado en develar y en nombrar la razón inherente al mundo: el logocentrismo se fundamenta en la certeza de la absoluta identidad de ambas tareas, ya que «al nombrar se devela y al develar se nombra». Supuestamente inscritas en la lengua y sedimentadas en la consciencia, las verdades de la razón se interpretan como reveladoras del Ser del mundo, vale decir, de su sentido último. Sentido que el lenguaje representa al representar el mundo. Efectivamente, en el lenguaje el hombre ha creído apresar la esencia de lo real.

De este modo, e inevitablemente, el universo de signos acaba confundiéndose con la realidad, ya que ésta sólo es vivida en la medida y de la manera en que es nombrada. Obviamente, el ser olvida que el lenguaje simplemente mediatiza su contacto con el mundo. Al codificar su experiencia, la criatura humana, de hecho, «crea» el mundo y al mismo tiempo, sin embargo, reifica y aliena su creación, puesto que la interpreta como algo pre-establecido, a priori al existir concreto. Algo que le es posible develar bien sólo apoyándose en el logos. De ahí que el hombre de Occidente haya entronizado su interpretación del cosmos, entronización que lo mueve a reprimir, a desterrar del nivel consciente todo lo que no encaje en el orden revelado. 
Fundamentalmente racionalista y, por ende, representacional, la cultura logocéntrica, en efecto, ha reprimido brutalmente todo aquello que no conforma con los cánones que la soportan: todo aquello que por irracional se muestra innombrable y/o que por innombrable se revela irracional.

Depositaria de la irracionalidad del mundo (y, por tanto, de su no representabilidad o innombrabilidad), la mujer ha sido sistemáticamente excluida de la tarea de nombrar y develar la esencia de lo real: es evidente que el aparato conceptual de Occidente, así como los sistemas sígnicos (y simbólicos) que lo representan, son creaciones eminentemente masculinas. Desde siempre, el hombre ha desposeído a la mujer de su facultad de interpretar $y$, por consiguiente, de crear el mundo.

En conclusión, el logocentrismo es esencialmente falocéntrico y la erección del logos se corresponde a la erección del falo. Esta doble erección simboliza la voluntad de dominio que define al hombre de Occidente y que lo impele a dividir para conquistar, explotar y violar al mundo, y, al mismo tiempo, para conquistar, explotar y violar a la mujer.

Además de nombrar y representar el universo, por tanto, el falogocentrismo lo fragmenta y dicotomiza; vale decir, lo ordena en base a una serie de términos en oposición. Mientras se privilegian los términos que acuerdan con el logos y con el falo, se denigran los que los contradicen.

De hecho, la dicotomización jerarquiza, y al jerarquizar crea los dioses del culto falogocéntrico: las verdades pre-establecidas, los modelos preexistentes y las leyes pre-fabricadas que pre-determinan la experiencia y que últimamente instalan al ser en la agobiante linearidad de un universo condenado a reiterarse infinitamente. En tanto fetichiza un orden que se juzga a priori, el mundo de Occidente revela su obsesión por el pasado y por la tradición. Nótese que el pasado es también representable, capaz de repetirse en el presente: de este modo, las verdades oficiales se acumulan, y al acumularse, paulatinamente fraguan la tradición.

En última instancia, sin embargo, el falogocentrismo escamotea el tiempo presente, tarea que es parte esencial de la represión generalizada que lo sustenta. Escamoteada la única dimensión temporal en que el ser realmente es y está en el mundo - vale decir, el único tiempo desde el cual le es dado operar para transformar o recrear el universo-, el hombre se despoja él mismo de su potencialidad creadora.

En efecto, la represión de Occidente invade los más recónditos espacios de la experiencia para acabar reprimiendo al represor. Hechizado por los productos de su intelecto, el ser alinea y reifica en ellos su potencial creador. Reprimida su creatividad, el hombre termina reprimiendo el he- 
cho obvio de que los objetos de su culto son su propia creación. Es evidente que si el hombre ha desposeído a la mujer de su inherente virtualidad creadora, también se ha desposeído a sí mismo, a la materia y al lenguaje de su inherente creatividad.

Al pretender haber aprehendido el Ser del mundo y su sentido trascendente, el falogocentrismo se ha naturalizado, ha devenido eternidad inmovilizadora. De este modo, el ser humano se ha convertido en pasivo espectador de una realidad que se interpreta como algo «dado» y en cuya creación y recreación ya no le es permitido participar.

Lo que el falogocentrismo esencialmente ha reprimido, sin embargo, es la energía creadora que es inmanente al mundo y que ha desencadenado tanto el feminismo como el desconstructivismo y la física cuántica. En las honduras de la mente, el lenguaje y la materia bulle la fuerza de vida que desafía al logos y que se encarna en la mujer.

Es en estas honduras donde bucean dos eruditos contemporáneos cuyas investigaciones del lenguaje, la conciencia y la materia complementan y confirman la postura feminista. Me refiero al texto de Jacques Derrida sobre différance y al trabajo del físico David Bohm sobre el orden implícito o no manifiesto.

Ambos escritos evidencian sorprendentes semejanzas de interpretación, pero mientras el de Derrida examina los abismos del lenguaje y la conciencia, el de Bohm incursiona en los abismos de la conciencia y la materia: en las entrañas de la experiencia el firme universo falogocéntrico se des-sustancializa y el Ser del mundo, así como su «último sentido», deben entenderse sólo en términos de su devenir, de su continuo hacerse. Tanto différance como el orden no manifiesto o implícito señalan, por tanto, los recónditos territorios que «anteceden», por así decirlo, a la conciencia razonante, al lenguaje y a la materia y que revelan, en última instancia, una inaudita y subversiva causalidad.

Para la elaboración de différance Derrida se sirve, por un lado, de la noción saussureana de la lengua como sistema de diferencias; se apoya, por el otro, en la doble acepción de postergación y diferencia que entraña el verbo diferir. Explicitada en términos de lo que no es («no es ni palabra ni concepto"), ya que es innombrable e irrepresentable, la différance señala, por un lado, la energía que desde los abismos del lenguaje y la conciencia produce las diferencias; indica, por el otro, el ininterrumpido juego de las mismas. Différance revela, por tanto, la energía que por siempre difiere de sí (que es siempre diferente de sí) y que sin cesar se difiere o se posterga; ya que incesantemente difiere o posterga su sustancialización. La vocal «a» que reemplaza la «e» segunda del término francés différance (una «a» que por inaudible no se deja apropiar por el logos) 
alude, en última instancia, a la energía que excede y desborda el orden logocéntrico.

Desde el fondo de la experiencia, différance opera, en palabras de Derrida, como la «causa constituyente» que desde los espacios más recónditos incesantemente se constituye e incesantemente reconstituye la experiencia. Es por eso que Derrida considera a la conciencia razonante y al lenguaje como «efectos» de différance.

Similarmente, Bohm propone que las formas que integran el orden manifiesto o explícito son «abstracciones» del orden no manifiesto o implícito. Interpretado como «causa constituyente», el orden no manifiesto alude a la energía que desde los abismos de la conciencia y la materia sin tregua se constituye y sin tregua reconstituye el mundo. Apelando a la jerga desconstruccionista, se la puede definir como la energía que por siempre difiere de sí y que por siempre se difiere de este modo continuamente, soslayando su sustancialización. (Bohm considera que así como la materia es energía, también lo es la conciencia, bien que esta última sugiere una energía extremadamente sutil.) Al igual que différance, por tanto, el orden no manifiesto constituye lo no nombrable y no representable y, por ende, presupone una invalidación del logos. Al igual que différance, el orden no manifiesto también sugiere un exceso o desborde que hace temblar los cimientos del edificio cultural.

Tanto el desconstructivismo como la física actual, por tanto, cuestionan la primacía del universo material: a medida que la atención del estudioso desciende a las entrañas de la realidad, ésta comienza a vivirse como un sistema abierto que evoluciona creativamente desde sus propios abismos y no mecánica y determinísticamente desde un tiránico pasado. Y estos abismos conforman precisamente el reino misterioso asociado a la mujer.

Considerando que contradice al logos, la experiencia femenina es equiparable a différance y al orden no manifiesto. En uno de sus excelentes trabajos sobre el desconstructivismo, Jonathan Culler hace notar, además, que en tanto portadora de una bisexualidad intrínseca, ya que posee simultáneamente los dos órganos (el clítoris es un menudo pene), la mujer encarna el modelo general de la sexualidad. De ahí que sea posible postular, siguiendo el modelo derridiano, una proto-hembra o archi-hembra que se exhibe como la «causa constituyente» de los diferentes modos de sexualidad. Ello induce a considerar al hombre como un «efecto» o «una instancia particular» de la mujer, de este modo radicalmente cuestionando la supremacía del falo.

Más aún: la proto-hembra, al igual que différance y que el orden implícito o no manifiesto, se resiste a ser nombrada o representada $y$, por tanto, escapa a las determinaciones ideológicas y lingüísticas del falogo- 
centrismo. «En un sentido profundo - afirma Julia Kristeva-, la mujer... es algo que ni siquiera pertenece al orden del Ser... En la mujer veo algo que no puede representarse, algo que no se deja decir y que trasciende las nomenclaturas e ideologías» de la cultura. La mujer ha patentizado siempre la potencia de vida (el frenesí dionisíaco), que, desde las entrañas de lo real, continuamente excede y desborda el modelo logocéntrico. De ahí las repetidas acusaciones de locura, de brujería o de neurosis de que ha sido tradicionalmente objeto la mujer.

Es de notar, sin embargo, que el juego de la diferencia (diferencia sexual) por el que la proto-hembra se constituye y se reconstituye sin cesar no privilegia ni al varón ni a la mujer, sino que más bien exalta la interrelación recreadora entre los sexos. A diferencia del falogocentrismo que fragmenta, dicotomiza y jerarquiza el mundo, la experiencia feminista que la proto-hembra encarna busca integrar, relacionar y des-jerarquizar o descentralizar la realidad. Así entendido, el feminismo postula una «práctica sexual» que perennemente haga y re-haga el mundo al actualizar la virtualidad relacional entre el orden tradicionalmente consagrado y el tradicionalmente denigrado.

No es casual que Bohm, por su parte, haya propuesto la noción de holoflux para expresar su visión de la realidad como una totalidad en movimiento y en perenne cambio. En última instancia, el holoflux sugiere la puesta en marcha de la interacción recreadora entre el orden manifiesto y el no manifiesto, a la par que hace hincapié en el hecho de que la relativización del primero des-jerarquiza o descentraliza el mundo: lo abre a una continua vehemencia creadora que compromete fundamentalmente al ser.

Tampoco es casual que Derrida y los desconstruccionistas interpreten la realidad como tejido o texto que infinitamente se teje o se desteje en base a la interrelación renovadora entre los órganos tradicionalmente polarizados: la conciencia y la inconsciencia, el lenguaje y différance, el mundo de afuera y el de dentro, la superficie y los abismos. De hecho, la práctica textual inaugura un proceso que incesantemente desconstruye y reconstruye el mundo.

Ya nos refiramos a la propuesta desconstructivista sobre la productividad textual o a la de Bohm sobre el holoflux, la noción de una realidad que se reconstruye infinitamente desde sus propios abismos destaca el papel que en ella desempeña el ser: es evidente que la realidad sólo es «transformable» en la medida en que el sujeto de la experiencia conciencie la potencialidad creadora que íntimamente comparte con el mundo, con su objeto. Bien entendida, la práctica textual (y la del holoflux) desvirtúa la polaridad sujeto/objeto, que es también fundamental para el logocen- 
trismo. Más que la necesidad de ejercer control sobre el mundo, el ser ha comenzado a vislumbrar la posibilidad de actuar en relación a él. La voluntad de dominio ha empezado a ceder lugar a la voluntad de participar en el proceso de continua recreación de lo real. Es evidente que la experiencia contemporánea (tal como la propone el desconstructivismo y la física) devuelve a la criatura humana su largamente alienado poder de creador: lo arranca de la fosilizante veneración de las formas del pasado y lo coloca en la perennidad recreadora, en la siempre actual inminencia del presente.

Claramente, la noción de productividad textual (y la del holoflux) relativiza el pasado y desvirtúa la experiencia lineal del tiempo haciendo hincapié en la única real temporalidad: la del presente. Bien entendidas, la práctica textual y la del holoflux sólo ocurren (sólo pueden ocurrir) en el eterno presente: en el «siempre ya» ahora del existir concreto.

En efecto, si la realidad se reconstituye eternamente desde el eterno presente, es porque el eterno presente se constituye y reconstituye eternamente. Desafiando la experiencia lineal que ubica al saber en una serie de sucesivos presentes, el mundo contemporáneo desconstruye el presente al interrelacionarlo con el pasado y también con el futuro: estos últimos se interpretan como «existiendo» (o «reverberando», en palabras de Bohm) en los abismos del presente, en las honduras del inconsciente.

Al decir de Bohm y Derrida, los trazos del pasado (y asimismo los del futuro, ya que los tiempos humanos «coexisten» en différance y en el orden implícito; vale decir, en el fondo de la experiencia) operan desde las profundidades del desconstruido presente. El pasado incide en el presente, aunque no linealmente, como incontrovertida verdad pretérita que éste reitera y representa, sino más bien como verdad des-sustancializada que el presente reconstituye y transforma al reconstituirse él mismo. (Nótese que en este contexto la posibilidad futura también se reconstituye al reconstituirse el presente). Más que causado por el pasado, el presente se produce a sí mismo desde los abismos de la experiencia, abismos que potencian, por tanto, no sólo todas las posibles formas que al manifestarse moldean lo real, sino también todos los posibles tiempos que al actualizarse informan la experiencia. Y este momento presente, el «siempre ya», ahora desde el cual el mundo se reinventa sin tregua, se asocia no sólo con la práctica textual y el holoflux, sino también con la práctica sexual, la cual, ya lo dijimos, compromete en términos de igualdad al varón y a la mujer. Sin embargo, ya que la irrupción de lo femenino es lo que pone en marcha la práctica sexual, el tiempo presente tiende a asociarse más entrañablemente con la mujer. Depositaria de la creatividad del mundo, la hembra es el presente. 
En efecto, la potencia de vida que la mujer implica, y que escapa a los sistemas linguíísticos e ideológicos logocéntricos, concurrentemente desafía las formas del pasado y "se instala» en el eterno presente. La periódica irrupción de lo femenino en el escenario de Occidente (encarnada en la periódica aparición de los «terroristas de la cultura», sean éstos hembras o varones) desconstruye el presente logocéntrico a la par que desvirtúa las verdades del pasado y que transforma la posibilidad futura. De ahí que haya sido imperativo silenciar sistemáticamente la potencia de vida que la hembra representa.

Lo cierto es que al silenciar la dimensión femenina el hombre ha reprimido la energía creadora que desde el fondo del eterno presente eternamente busca recrear el mundo. Cualquiera que sea su índole, un movimiento de liberación que persiga transformar radicalmente el mundo y que no integre la rebelión feminista está condenado a fracasar: si la realidad es una totalidad interrelacional en perenne mutación, la represión de una de sus innúmeras facetas simultáneamente reprime a las demás.

Es evidente que el mundo de Occidente se halla en el umbral de una nueva época: una época en la que le toca a la mujer asumir el papel decisivo que la tradición le ha arrebatado y negado a lo largo de la historia. De mera espectadora de un mundo elaborado por y para el hombre, la mujer se ha de convertir en activa participante en la creación de un mundo que acoja con igual deferencia al varón y a la mujer. Un mundo que al redimirse de toda castrante represión se convierta en espacio energizado, por siempre transformable y por siempre transformante. Un mundo perennemente abierto a una auténtica y creativa evolución. 